\title{
OS REALITY SHOWS E A QUEBRA \\ DOS MARCADORES ESPAÇO-TEMPORAIS \\ NA COMUNICAÇÃO SOCIAL
}

SIMONE ANTONIACI TUZZO

RONALDO NUNES LINHARES

Simone Antoniaci Tuzzo é Doutora em Comunicação pela Universidade Federal do Rio de Janeiro - UFRJ - e docente do curso de Relações Públicas da Universidade Federal de Goiás - UFG - Goiás. E-mail: simonetuzzo@hotmail.com.

Ronaldo Nunes Linhares é Doutor em Comunicação pela Universidade de São Paulo - USP - e docente dos cursos de Graduação e Pós-Graduação da Universidade Tiradentes - Unit - Sergipe. E-mail: ronaldonl@uol.com.br.

\section{RESUMO}

O fascínio pelos Reality Shows e os marcadores espaço-temporais que definem a distância entre o real e o espetáculo são temas importantes neste artigo. A reflexão sobre o crescimento do número de programas de televisão nesse formato e a consequente inclusão de anônimos em aventuras televisivas, transformando-os em modelos de comportamentos e de consumo para a sociedade além de desconstituir marcadores positivos na relação comunicativa entre a realidade e a imaginação. Assim como a curiosidade é o ponto-chave do sucesso desse formato televisivo em que o texto e o roteiro são uma trama construída a cada dia, editada por um grupo televisivo que busca a audiência numa sociedade mundializada, onde tudo e todos são e não são, este tipo de programa cria um novo espaço de participação pública a partir da exploração das intimidades, atenuando a linha divisória entre o real e o imaginário e tornando a imaginação um importante elemento no processo de mercantilização e espetacularização da comunicação.

Palavras-chave: Televisão; Reality Shows; comportamento; mundialização, marcadores espaço-temporais

\section{Introdução}

Para se pensar a televisão brasileira hoje, parece-nos possível utilizar algumas reflexões propostas por Maquiavel, principalmente quando este analisa as características naturais do homem que influenciaram a construção da ação política. Claro que, neste caso, deve-se observar o contexto, ou seja, a crítica à ideia da ação humana como reprodutibilidade da ação divina, ou as necessidades de retomar o conceito de Estado como força, unidade e nação que na Itália da época parecia impossível. De qualquer forma, a ideia 
pragmática de que os fins justificam os meios nos parece muito interessante e aplicável ao produto televisão nos dias atuais.

Em se tratando da televisão, estamos diante de uma tecnologia de comunicação que nos surpreende a cada dia, não pela tecnologia em si - esta inova, mas não sai do seu roteiro - mas pela linguagem, a capacidade "mediadora privilegiada entre o homem e a realidade, fazendo a mediação entre o social, o individual e o inovador no pensamento individual [...] a linguagem pode influenciar o nível de abstração e o nível de generalização do pensamento humano" (BACCEGA, 1998 , p.68), ou seja, aquilo que efetivamente comunica. Nesse caso, devemos romper com o mediacentrismo, que resultou numa "identificación de la comunicación com los médios [...], compreender la comunicación como funcionam las tecnologias o dos 'aparatos' pues ellos hacen la comunicación, la determinan" (MARTIN-BARBERO, 2001).

Consideramos aqui como ponto de partida de nossa reflexão a ideia de comunicação como processo de desenvolvimento das práticas sociais. Nesse sentido, Barbero observa que essa postura implica uma ruptura e descentramento quanto às visões comunicacionais, mediacentristas e com o que ele chama de "marginalismo de lo alternativo". ${ }^{3}$

No campo das práticas sociais, a comunicação produz um conjunto de signos que nos faz reconhecer o dito e o interdito, ligando e religando diversos significados e significantes. É através de um processo simbólico de percepção dos sentidos que podemos criar os modelos ou esquemas abstratos com que nos equipamos para apreender o mundo, modelos esses que funcionam como mediações, mais ou menos complexas, que fazem os processos perceptivos funcionarem também como processos interpretativos. Dessa forma, os processos perceptivos são caracterizados como processos de linguagem (SANTAELLA, 1986, p. 2).

No caso da televisão, esse processo simbólico tem nos surpreendido, principalmente quando da construção dessa linguagem como mercadoria, criando uma simbiose entre ditar modelos e comportamentos para consumo coletivo ou se apropriar destes para criar seus roteiros de programas: uma relação de interferência entre produção e consumo. Ou, mais que isso, uma relação de negociação de sentidos, característica dos processos de sociabilidade. Trama que forma os sujeitos em suas lutas e suas negociações cotidianas com o poder e as instituições sociais (MARTIN-BARBERO, op. cit).

Elementos importantes nessa relação de comunicação social que se estabelecem através dos meios de comunicação, em especial a televisão, são misturados, revistos e revirados ao bel prazer de grupos e das novas necessidades de um mercado ávido por novidades, que se alimenta delas de uma forma absoluta e absolutizante, reduzindo tudo e todos ao espetáculo. Aqui, o espetáculo é entendido como

o momento em que a mercadoria chega à ocupação total da vida social. Tudo isso
3 Mais informações sobre essa reflexão ver "De los médios a las practicas" in Las comunicacións desde las practicas sociais, cuadernos de Comunicación y Practicas Sociales, Universidad Iberoamericana, 1990. 
é perfeitamente visível com relação à mercadoria, pois nada mais se vê senão ela: o mundo visivel é o seu mundo. (...) O espetáculo é uma permanente guerra do ópio para confundir bem com mercadoria; satisfação com sobrevivência, regulando tudo segundo as suas próprias leis. Se o consumo da sobrevivência é algo que deve crescer sempre, é porque a privação nunca deve ser contida. E se ele não é contido, nem estancado, é porque ele não está para além da privação, é a própria privação enriquecida. (DEBORD, 1997, p. 30).

A televisão não só se transformou no novo lago narcisista, ou seja, uma forma de enxergar no outro o que se gostaria de ser, mas criou uma novidade: ao espatacularizar o cotidiano, o comum, criou a sensação coletiva de que o indivíduo comum pode fazer parte dela não somente como consumidor, mas como ator, interlocutor, ou seja, produtos midiáticos que permitem que qualquer pessoa possa ser o astro, nem que seja por um dia; assim, não só enxergar no outro o que se gostaria de ser, mas servir de modelo.

Segundo Canclini (1997, p. 28), a novidade apresentada a partir da segunda metade do século XX "é que essas modalidades audiovisuais e massivas de organização da cultura foram subordinadas a critérios de lucro, assim como a um ordenamento global que desterritorializa seus conteúdos e suas formas de consumo"; completa ele que esse processo de conjunção dos processos de des- regulamentação, privatização e concentração transnacional das empresas "diminuiu as vozes públicas" em todas as instâncias sociais.

Necessitaríamos de novos olhares que reordenassem as concepções de público e privado como espaços de ação política ou de construção de novos limites entre privado/íntimo?

Um modelo de eterno devir, de passagem, de aparências, um modelo de massa. Podemos afirmar aqui que este modelo de comportamento tornou-se padrão de produção. No caso específico da televisão, muito mais que a mensagem, a linguagem e a estética são determinantes para a compreensão coletiva de conceitos. A linguagem torna-se pasteurizada, com a criação de ícones determinantes para a compreensão coletiva e modelo padrão para o glamour, "arroz de festa" estilizado e mascarado no gosto do consumidor médio.

No espaço da produção e consumo de cultura, as relações são bem mais complexas. Reconhecese que "ao consumir também se pensa, se escolhe e se reelabora o sentido social" (CANCLINI, op. cit). Diferentemente das outras áreas comumente rotuladas de consumo, a apropriação de bens e signos culturais proporciona, numa relação dialética, a retomada de conceitos, sua estruturação e reestruturação e, consequentemente, possibilita a construção de formas mais ativas de participação.

No caso da comunicação, "constrói-se uma ideia de comunicação perfeita. No entanto, produzir a mensagem não é uma atividade tão transparente como 
parece" (HALL, 2003, p. 354). $O$ processo de comunicação não pode ser visto como um processo linear, e a recepção da mensagem não ocorre de maneira aberta e transparente como se pretende fazer acreditar.

Estaríamos diante de um novo telespectador? Um novo consumidor de bens simbólicos?

\section{Realidade $\mathrm{x}$ fantasia no espetáculo comum da TV}

Num processo de magia possível, sonho, realidade e negociação, tem início a produção em escala de reality shows de toda espécie. Desde o final dos anos 90, nunca a televisão apresentou tantos programas na linha da construção de "verdades" e de aventuras vividas por anônimos, e nunca tantos anônimos tornaramse modelos de comportamento e de consumo.

Ainda que seja fantasiosa essa realidade, tendo em vista o pequeno número de participantes que esses programas possam absorver, existe a magia possível, a utopia que vira sonho e que (um dia) poderá se tornar realidade. Ou o inverso, a sofrida realidade, que pode ser travestida, tornar-se sonho, programa de TV, virtualizar-se, sair de um corpo social e incorporar-se, via estética televisiva, na vitrine do mundo. Invertemos os caminhos no processo de publicação do privado, extrapolamos o limite, entramos no íntimo e o conduzimos à posição de coisa pública.

Se pensarmos no binômio reality show, encontraremos os seguintes significados (MI-
CHAELES, 1989, p. 239 e 266; HOUAISS, 2001, p. 2391 e 2565):

Reality - realidade; verdade; qualidade ou característica do que é real; o que realmente existe.

Show - espetáculo; exposição, exibição armada para angariar interesses ou estimular vendas; falsa aparência.

Muito mais que uma ilusão de espetáculo real, o próprio título desse tipo de programação já confirma uma dicotomia, uma realidade fabricada. Contrapondo o significado das palavras, recriase uma nova ideia, um novo conceito: real é o que realmente existe como exibição armada para angariar interesses ou estimular vendas. A televisão pode criar sua própria realidade ou espetacularizar o real, a fim de torná-lo bem simbólico de consumo. Não a realidade de fato, vivida pelo público, mas a realidade midiatizada, do espetáculo, da nova forma de vida.

Certamente a televisão já passou por várias transformações desde o seu surgimento.

Em uma análise do avanço desse processo, podemos observar a mudança da televisão nos últimos 50 anos.

O impacto que causou na sociedade desde o seu surgimento, a sua evolução já prevista desde a década de 60 por McLuhan, até a sua transformação na década de 80, com o aparecimento de novas mídias que construíram um conceito de multimídia que se desenvolve durante a década de 90, mostra a evolução rápida e constante da televisão. Nesse espaço de tempo a TV 
sua competência como forma de linguagem comunicacional, adotando características dos meios anteriores a ela e dos novos, modificou-se, reestruturando-se e reorganizandose, e teve a força de continuar suprema diante de um quadro tecnológico e informacional inédito. (TUZZO, 1998, p. 130).

Estamos, portanto, diante de um processo interessante. A televisão é uma mídia mutante, cujas características mudam através do tempo e dos lugares, fruto não somente da evolução tecnológica, mas das vivências e transformações de sentido características do processo de construção da cultura. Mais recentemente, através dos reality shows, a TV estrutura novos links, elos que ligam o desejo, as necessidades do consumidor num caminho inverso para a construção do produto. Numa situação hipoteticamente real, mas não real de fato.

Os reality shows não são menos fabricados do que as telenovelas, a exemplo da Casa dos Artistas, No Limite, A Fazenda e Big Brother. O aparato tecnológico que envolve ambos os produtos midiáticos assemelhase em iluminação, edição, superprodução e espetacularização. A principal diferença é que nas telenovelas as falas e ações dos atores são previamente descritas por um autor, e nos reality shows as falas são criadas espontaneamente pelos atores, num discurso construído, principalmente, no processo de edição. O direcionamento, contudo, continua a existir, quer seja no processo de edição das imagens, quer seja na indução de comportamento criado pelo espaço físico proposto para o convívio dos participantes/ atores, quer seja pela produção de festas, jogos, brincadeiras imposta pela emissora.

Dentro dessa perspectiva, podemos tentar entender no campo da recepção: qual o gosto do público? O que pensam? Quais conceitos morais e éticos alimentam as ações do cotidiano e do corpo social? Como as práticas sociais se desenvolvem a partir dos processos de negociação de sentidos no campo da comunicação?

Para Martinho (2003, p. 1921), a análise da veiculação das estratégicas simbólicas pressupõe o conhecimento da origem institucional do produto. Além disso, cabe às ciências sociais descobrir as regularidades dos fenômenos e determinar-lhes critérios de significação. Contudo, o estudo do comportamento social do indivíduo, frequentador, simultâneo, de distintas instâncias da vida, presente em distintos universos sociais, com regras próprias, não pode ser entendido através da fixação de meia dúzia de teoremas.

Curiosamente, a TV consegue agregar indivíduos absolutamente distintos, com formas existenciais distintas; a televisão consegue "introduzir em todas as casas um mecanismo focalizado e coletivo de processamento de informações" (KERCKHOVE, 1997, p. 88). Assim, a televisão consegue "prolongar o pensamento privado para uma memória ativa coletiva ao reproduzir, num ecrã exterior, as principais combinações sensoriais que utilizamos para criar 
internamente o sentido" (Idem, 1997, p. 88).

Em nenhum momento as novas tecnologias da informação têm-se demonstrado como ameaças para a televisão. Pelo contrário, sua versatilidade, seu poder de adaptação camaleônica, consegue fazer com que absorva todos os signos consagrados pela sociedade em cada uma das novas tecnologias e consegue se apropriar destas, modificando a sua linguagem e o seu desenvolvimento.

Até pouco tempo atrás, visitar os clientes, entender o consumidor era um processo de contato real, mesmo que isso se desse via telefone. Isso hoje também passa para a televisão, que soma telefonia, telemática e internet num processo de ligar e realizar o texto televisivo ao leitor consumidor, através de uma concepção nem sempre real de interatividade.

Trouxemos então à TV as conversas de comadre. Já não era somente um aparelho e uma linguagem, hoje é muito mais, é um amigo. É possível dizer o que se pensa disto ou daquilo. $\mathrm{O}$ ato de se mandar beijos aos parentes e amigos no programa de domingo, sob as batutas do Faustão, da Eliana ou do Gugu, anteriormente iniciadas com o Programa Sílvio Santos, ganha cada vez mais força.

Essa nova forma de consumo ou participação do consumidor faz parte do processo de construção das identidades pós-modernas. Identidades que se caracterizam por ser transterritoriais e multilinguísticas - poderíamos afirmar - são também pluriculturais e, na maioria das vezes, grotescamente democráticas. Estruturam-se pela lógica do mercado, operam mediante a produção industrial de cultura, sua comunicação tecnológica e pelo consumo diferido e segmentado de bens (CANCLINI, 1997, p. 35).

\section{Construindo discursos sobre os reality shows}

Em uma rápida enquete feita com os alunos de Comunicação Social da Universidade Tiradentes - Unit - sobre o impacto dos reality shows na sociedade brasileira, verificamos que grande parte deles não se atenta ao conteúdo quando questionada sobre a existência de tais programas. Pelo contrário, eles limitam suas críticas e observações à forma, desconsiderando o impacto que esse tipo de programa tem causado na sociedade ou como ocorre o processo de construção do discurso.

Quando questionados sobre o que são os reality shows, os alunos não trabalham com a ideologia do programa e, ao se limitarem ao formato, afirmam somente que se trata de uma forma de apresentar a privacidade das pessoas. Não há menção ao padrão globalizado do programa. Os reality shows são um exemplo da mundialização de modelos culturais influenciados pela ideologia globalizadora das mídias. Um programa produzido em massa que, finalmente, adaptando-se à pluralidade cultural, utiliza-se das mídias de comunicação para, interferindo no local, construir um padrão global de cultura, gostos e, principalmente, sentidos. 
Em muito a febre dos reality shows amplia e populariza o modelo das novelas e dos seriados e desconstrói as barreiras culturais que separam o real e o imaginário.

Alberto Munari (1992) define essas barreiras como "marcadores espaço-temporais", que são os limites estabelecidos pela determinação bastante demarcada do espaço e do tempo previamente fixados para os espetáculos e a divulgação da imagem. Com o passar do tempo, essas regras culturais deixaram de existir, perderam a racionalidade, permitindo que a imagem e o espetáculo ultrapassassem os limites determinados para diferenciar o real da representação mimética do real, definindo as práticas culturais das sociedades pós-modernas.

Para Linhares (2007, p. 38), a partir desse conceito, a televisão rompe com

os limites, e a consciência adentra num espaço vazio, onde a liberdade não tem limites, mas sem eles não nos dá certezas da existência da liberdade. A tecnologia como suporte para a comunicação humana deixou de ser a extensão do corpo para tornarse o próprio corpus. Destruiu conceitos, criou um tempo técnico, um tempo não humano, sem identidade. Reduziu espaços e virtualizou-os, deslocou lugares para espaços antes inimagináveis e inexistentes. Destruiu os marcadores racionais e significativos da cultura, entorpeceu consciências. A língua engoliu a linguagem para, dessig4 Conceituar língua, linguagem e fala. nova comunicação ${ }^{4}$. Essa espécie de anarquia produzida pela imagem hoje pode alterar as formas de consciência e dificultar a percepção do real enquanto real.

Na sociedade da imagem e da virtualização do real, o sentimento de indefinição do real é uma constante e uma ameaça, pois proporciona uma indefinição de termos, uma colisão de polos que faz com que em nenhum lugar haja a possibilidade do juízo do valor e muito menos as certezas do terreno seguro da realidade. Tal qual a telenovela e seriados, o Reality manipula e seleciona imagens e discursos mais ou menos apropriados ao público, mas nunca distante do mundo da mercadoria e, portanto, nunca abaixo do espetáculo. Para Silveira, (apud Linhares, op. Cit.) "a questão não está na imagem, está na seleção do que é veiculado e do que é excluído pelo poder", está nas palavras que são utilizadas para dizer o fato.

Esse processo de ruptura dos marcadores espaço-temporais se aprofunda com o avanço da tecnologia e das linguagens audiovisuais e com a concorrência do mercado de entretenimento. Diferente do teatro, do circo e outros, os novos espaços tecnológicos de entretenimento e espetáculo transformaram o modo de ver do espectador. Aqui, as negociações e mediações são outras, acontecem de modos e de formas diferenciadas, criando uma nova relação entre o real e o imaginário. Para Baudrillard, na sociedade contemporânea, "o espectador só se torna realmente 
ator quando há estrita separação entre palco e plateia. Tudo, porém, concorre, na atualidade, para a abolição desse corte: a imersão do telespectador tornase convival, interativa". (BAUDRILLARD, 1997, p. 146)

Ainda no tocante à enquete dos alunos, raros citam ou percebem o fato de o discurso imagético ser selecionado e editado por uma produção, respondendo a um objetivo cada vez mais dependente dos humores do mercado. Raros também se lembram que as imagens e as ações são produzidas a partir de uma determinação de comportamento direto ou indireto, natural ou superficial, pré-estabelecido pela produção do programa.

Mas por que, de fato, esse formato de programa causa tanta admiração e conquista sucesso na sociedade não só brasileira, mas em vários países na América e na Europa? E o que verdadeiramente pode significar no campo das práticas sociais o consumo ${ }^{5}$ desse novo produto da cultura televisiva? Estas e outras questões devem ser respondidas para ampliar nossa percepção sobre o papel da comunicação, através da linguagem televisiva na prática social do homem contemporâneo.

Citando Hall, é possível entender a assistência deste tipo de programa quando pudermos entender "o processo de comunicação como uma estrutura produzida e sustentada através da articulação de momentos distintos, mas interligados - produção, circulação, distribuição/consumo, reprodução" (op. cit. p. 387), identificando nesse processo aquilo que o define como mercadoria num dado sistema sociocultural e econômico.

A partir do momento em que a televisão se transforma em centro da vida, a vida das pessoas passa a fazer parte dela. É como se o objeto de adoração do centro da sala fosse absorvido de tal forma pelos consumidores da mídia que já não há mais uma diferença entre estar em frente ou dentro do aparelho. Suas vidas, obrigatoriamente, também se transformam em centro da TV, vendo na intimidade alguém igual ao telespectador. Vivenciando situações hipoteticamente iguais às do público, este se sentirá, também, um astro, porque passa a fazer parte desse mundo da televisão.

Vivemos hoje na televisão dois formatos de reality shows: aqueles em que os personagens são pessoas comuns, anônimas, da sociedade, que sonham em ser celebridades e celebridades que se submetem a uma exposição, a fim de multiplicarem sua admiração pelo público; e, no segundo formato, a televisão cumpre o papel de alimentar o sonho do público.

Cada fã sonha com um momento íntimo com o seu ídolo, até porque isso seria uma forma de conquistar aquilo que todos querem. Numa dicotomia, a existência do ídolo só é possivel porque muitos exaltam um mesmo personagem até transformá-lo numa celebridade ou herói midiático, reafirmando a necessidade do coletivo; porém, cada membro do processo sonha em se separar do grupo para viver uma emoção singular com aquele que precisa do coletivo para
5 Segundo Canclini, "o consumo é o conjunto de processos socioculturais em que se realizam a apropriação e os usos dos produtos" (CANCLINI, 1997, p. 53). 
se firmar no grande jogo da celebridade (TUZZO, 2005, p. 123).

Pensando nesse sonho coletivo de poder fazer parte da vida íntima do astro, a televisão cria uma forma de trazer o íntimo da celebridade para o fã através da própria $\mathrm{TV}$, já que o oposto seria impossível.

$\mathrm{O}$ primeiro formato de reality shows apresentado acima, no qual pessoas comuns passam a fazer parte da mídia, apresenta a possibilidade de criação de novas celebridades que sonham em fazer parte da televisão, viver o outro mundo, o mundo imaginário. Neal Gabler, numa citação do historiador Daniel Boorstin, diz que "os americanos vivem cada vez mais um mundo onde a fantasia é mais real que a realidade", advertindo que "estamos a ponto de nos tornar o primeiro povo da história a ter sido capaz de fazer suas ilusões tão vívidas, tão convincentes, tão realistas, que podemos até viver nelas" (GABLER, 1999, p. 11).

Nesse processo, a agilidade e a substituição de rostos e modelos é frenética. O show business precisa agora de elementos descartáveis e não somente de formatos de atores que duram. Assim, todos os dias temos novos rostos na TV, num mundo onde tudo passa a ser descartável. Essa é quase uma exigência da globalização.

Tomemos como paralelo casos de atores como Regina Duarte ou Tarcísio Meira. "Celebridades consagradas capazes de criar um deslumbramento coletivo e de despertar em cada indivíduo a certeza de pensar coletivamente, ao mesmo tempo desencadeando um sonho de ser o próprio ídolo ou de estar próximo de forma particular" (TUZZO, 1998, p. 138). Atores que construíram uma história para que se tornassem consagrados pelo público.

$\mathrm{Na}$ televisão, o sonho de poder estar com o ator consagrado ou com o recém-integrado ao mundo midiático é o mesmo. Já não há uma obrigatoriedade de que os atores necessitam primeiramente se firmar no cenário da mídia para depois poderem ser reconhecidos pela coletividade.

Além disso, no formato dos reality shows, tomando como exemplo o Big Brother Brasil, fica previsível quais integrantes permanecerão por mais tempo no programa, ou seja, aqueles que mais concentram características passíveis de alimentar as pautas dos demais veículos de comunicação, como revistas, jornais, rádios etc., a fim de continuar a cadeia de produção dos meios de comunicação. Nem a produção de um slogan escapa desse processo, ou seja, o "faz parte" ditado pelo vencedor da primeira versão do Big Brother Brasil na TV cumpre a mesma função do slogan "Jesus, me abana" da atriz da novela Caminho das Índias da Rede Globo.

Os reality shows conseguem ainda reunir características determinadas ou construídas do novo tipo de herói, distante do antigo, próximo do ideal popular, seja ele falso ou verdadeiro, produzido pelo povo ou para o povo.

A realidade de fato dos reality shows não está no programa, mas em quem está assistindo, aquele que consegue enxergar no 
programa o seu modo de vida. Como num jogo, os participantes desempenham papéis representativos de várias situações sociais, uma abordagem do mundo real, onde estão presentes negros, homossexuais, artistas, assalariados, etc. Assim, o sexo, o amor, a política estão representados por pessoas comuns. Todos estão ligados entre si de uma ou de outra maneira, controlados ou controladores da TV.

\section{À guisa de conclusão}

Os reality shows são programas que conseguem absorver muito mais participantes do que aqueles que estão na tela, pois os que estão em casa e podem votar para que alguém deixe o programa torna-se participante também. A curiosidade é seu ponto-chave. Assim, todos se envolvem, todos se preocupam e apresentam seus sentidos para cada ação, postura ou pessoa envolvida no jogo. A possibilidade que cada telespectador tem de eliminar os participantes do jogo é uma representação de poder, de supremacia sobre aqueles que estão confinados em um ambiente que se torna público e que se habilitam à vigilância e ao julgamento, serem vigiados e julgados por quem está do lado de fora. Sem dúvida, um grande espetáculo midiático.

No formato Casa dos Artistas, o poder torna-se ainda mais marcante, pois os anônimos podem determinar o destino de pessoas famosas, em que entram em conflito as expectativas despertadas pelo artista em seu público du- rante suas aparições públicas anteriores à realização do programa e às ações cotidianas desenvolvidas dentro da casa.

As questões são as seguintes: qual o limite entre a realidade do indivíduo e a virtualidade do personagem? Qual o limite da montagem? Qual o limite de uma realidade construída?

Estamos diante de um produto em que texto e roteiro são uma trama construída a cada dia. Um self-service de seres humanos. $\mathrm{O}$ que mais vende? Que postura ou pessoa o consumidor aceita melhor? No caso dos participantes, como devem ser? Que emoções devem apresentar? Que máscaras devem construir para convencer a plateia participante? Como devem entender as manifestações e opiniões dessa plateia que lhes chegam através dos votos, dos eliminados, da morte dos colegas no paredão?

Como partícipe e redator virtual desse programa, o público também vive o seu dilema pessoal, que é o de conseguir identificar se todo o comportamento do astro permanece o mesmo de suas atuações na TV, ou seja, até que ponto existe uma diferença entre o seu comportamento real, de um indivíduo que é público, e a manutenção de características de um personagem criado para o público. Em outras palavras, até que ponto as ações e reações dos participantes dos reality shows reforçam o que a mídia determina para a construção do astro ou são ações verdadeiras de um grupo de seres humanos confinados em um mesmo espaço por um tempo determinado.

Mais uma vez a televisão se 
supera, quer seja pela busca de mercado numa sociedade mundializada, onde tudo e todos são e não são, quer seja criando um novo espaço de participação pública a partir da exploração das intimidades. Eu me vejo em você, mas não o vejo em mim, por isso posso julgá-lo, condená-lo ao limbo ou ao sucesso. Os reality shows trazem novas questões sobre o processo de mediação, de negociação de sentidos produzidos no ato de ver televisão, em todas as classes sociais, mas trazem, principalmente, uma nova forma de comercialização com o público.

Lembra-nos o famoso vendedor da feira, sempre sugerindo que experimentemos o produto. Se não for bom, não leva. E mesmo não sendo bom, no caso da TV, permite que possamos melhorá-lo. Lidando com o ser humano, a televisão vende o imaginário, cada vez mais próximo do real. Transforma o real em sonho, cria a possibilidade de que todos podem, devem vencer, principalmente aqueles que nunca vencem na vida real.

Assim, podemos concordar com Guy Debord (1997) quando afirma que vivemos numa sociedade do espetáculo, num mundo realmente invertido, em que o verdadeiro é um momento falso. Para o autor,

o espetáculo que inverte o real é produzido de forma que a realidade vivida acaba materialmente invadida pela contemplação do espetáculo, refazendo em si mesma a ordem espetacular pela adesão positiva. A realidade objetiva está presente nos dois lados. Oalvo é passar para o lado oposto: a realidade surge no espetáculo, e o espetáculo no real. Esta alienação recíproca é a essência e o sustento da sociedade existente.

Tudo isso com a participação do público, elevado à categoria de astro principal. "Ligue, você pode denunciar, escolher, levar ao paredão, julgar, ser julgado e validar hábitos e posturas, conceitos e concepções". Formas de ser, que devem parecer cada vez mais com as suas identidades e possibilidades reais de ser. É uma pena que essa liberdade que custa apenas alguns reais na conta telefônica não é extensiva à vida comum. Nem sempre podemos, nem sempre vencemos, nem sempre a interatividade é fruto de uma atividade interna. Mesmo assim, no Reality Show da Vida Privada, VOCÊ DECIDE.

\section{Referências}

BACCEGA, Maria Aparecida. Comunicação e Linguagem: discursos e ciência. São Paulo: Moderna, 1998.

BAUDRILLARD, Jean. Tela Total. Mito - ironias da era do virtual e da imagem. Porto Alegre: Sulina, 1997.

CANCLINI, Néstor García. Consumidores e Cidadãos. Rio de Janeiro: UFRJ, 1997.

. América Latina: mercados, audiencias y valores en un mundo globalizado. In http://www.riosummit2004.com.br/noticias_full.asp?id noticias=1614\&idioma=por\&forum. Acesso em 03 fev. 2005. 
DEBORD, Guy. A sociedade do espetáculo. Rio de Janeiro: Contraponto, 1997.

GABLER, Neal. Vida, O Filme. São Paulo: Companhia das Letras, 1999.

GOMES, Guillermo Orosco (Org.). La comunicacion desde las practicas sociales. México: Universidad Iberoamericana, 1990.

HALL, Stuart. Da diáspora: identidade e mediações culturais. Belo Horizonte, UFMG/UNESCO, 2003.

HOUAISS, Antônio. Dicionário Houaiss da Língua Portuguesa. Rio de Janeiro: Objetiva, 2001.

KERCKHOVE, Derrick de. A pele da cultura. São Paulo: Relógio D’Água Editores, 1997.

LINHARES. Ronaldo Nunes. Gestão da Comunicação e Educação: o audiovisual no espaço escolar. Maceió, Ed. Ufal, 2007.

MARTINHO, Luiz Mauro Sá. Mídia e Poder Simbólico. São Paulo: Paulus, 2003.

MARTIN-BARBERO, Jesus. Dos Meios às Mediações. Rio de Janeiro: UFRJ, 2001.

. Oficio de Cartógrafo: travessias latino-americanas da comunicação na cultura. São Paulo, Loyola, 2004.

MICHAELIS. Pequeno dicionário inglês-português, português-inglês. São Paulo: Melhoramentos, 1989.

MUNARI, Alberto. De verdade o de mentira? In Videos culturas de fin de siglo. Madrid, Ed. Cátedra, 1992.

SANTAELLA, Lúcia. Semiótica e Conexões: o caso da psicanálise. Seminário apresentado na Universidade Metodista de São Paulo. São Paulo, 23 de abril de 1986.

SODRÉ, Muniz. Antropológica do Espelho: uma teoria da comunicação linear e em rede. Petrópolis: Vozes, 2002.

TUZZO, Simone Antoniaci. Deslumbramento Coletivo: Opinião Pública, Mídia e Universidade. São Paulo: Annablume, 2005.

. Revista Fragmenta. A televisão como meio de comunicação e não como forma de alienação. Aracaju: Universidade Tiradentes - Unit, 1998, p. 123-150.

Revista Caras. Especial Casa dos Artistas, 2000. 